\title{
Psychosocial Factors Associated with Domestic Violence Inflicted on Women by their Husbands at Kenge , Kwango Province, DRC
}

\author{
Jean Jacques Kisaka Ngimbi*1, Joel Kafumbi Katsiatsia ${ }^{2,4}$, Gertrude Lundu Yenamawu ${ }^{1}$ and Joseph \\ Mayituka Newa ${ }^{1,5}$ \\ ${ }^{1}$ Assistant, Higher Institute of Medical Techniques Marie Rein e Peace of Kenge, DRC \\ ${ }^{2}$ Chief of Works, Higher Institute of Medical Techniques Marie Queen of Peace of Kenge, DRC \\ ${ }^{3}$ Permanent Executive Secretary, Kwango Health Civil Society, DRC
}

${ }^{4}$ Nurse Caramal the project, Health Zone Kenge, DRC

${ }^{5}$ Physician, Kenge Reference General Hospital, DRC

*Corresponding author: Jean Jacques Kisaka Ngimbi, Assistant, Higher Institute of Medical Techniques Marie Reine Peace of Kenge, DRC

\begin{abstract}
ARTICLE INFO
Received: 豐 May 06, 2019

Published: May 23, 2019

Citation: Jean Jacques Kisaka N, Joel Kafumbi K, Gertrude Lundu Y, Joseph Mayituka N. Psychosocial Factors Associated with Domestic Violence Inflicted on Women by their Husbands at Kenge , Kwango Province, DRC. Biomed J Sci \& Tech Res 18(2)-2019. BJSTR. MS.ID.003130.
\end{abstract}

Keywords: Marriage; Repetitive domestic violence; Mors violence; Physical violence; Psychological violence

\begin{abstract}
Domestic violence against women by their husbands has several consequences, including conflict, divorce, prosecution, expenses, suicides, shared responsibility of children and even lack of supervision of children, to name but few. The purpose of this study is to determine the psychological and social aspects of domestic violence against women by their husbands. To accomplish achieve this goal, the study was assigned to identify psychological and social factors that influences the occurrence of domestic violence against women by their husbands in the city of Kenge. The study focused on data spread from March to July 2017 and the file Managed During a quantitative crosssectional survey by the technical interview. The sampling method was probabilistic, and the units selected randomly Were it. The sample size was 165 subjects and the proportion of domestic violence being white $0.11 \%$. Results show that violence against women by their husbands in a marital definition is associated with demographic factors (age); socio-economic factors (level of education and poverty); socio-cultural factors (types of marriage); behavioral factors (aggressive behavior since childhood, drug use) ; and environmental factors (boxes of family conflict). It is therefore recommended to the administrative and political authorities to sensitize the people to change Their attitude and behavior towards domestic violence. They shall also put in place guy humanisms that may help preventing violence at home.
\end{abstract}

\section{Introduction}

Domestic violence inflicted on women by their husbands has several consequences, including conflict, divorce, prosecution, expenses, suicides, scattering of children and even lack of supervision of children, to name a few. that. The purpose of this study was to identify the psychosocial factors associated with domestic violence against women by their husbands. To achieve this goal, the assigned objectives were to identify the psychosocial factors that influence the occurrence of domestic violence against women by her husband in the town of Kenge. This study covers data collected over the period from March to July 2017 during a cross-sectional quantitative survey by the interview technique. The sample of this study is probabilistic, selected in a simple random way. Its size's Eleven 165 subjects, while the proportion of domestic violence at $0.11 \%$. The results of the study conclude that violence against women in the conjugal roof by their husbands is associated with demographic factors (age); socio-economic (level 
of education, poverty); socio-cultural (form or types of marriage); Individuals (aggressive behavior since childhood, drug use) and environmental factors (history of family conflict). You have if recommended as administrative authorities and policy awareness to change his attitude and behavior towards domestic violence. They were member also established hoc mechanisms to prevent permanent year domestic violence. The man as head of household has the responsibility to protect all family members. My sadly, behavior that manifest it about a woman and her partner, the family environment can sometimes be deplorable [1]. The violence was the woman by her intimate partner, otherwise called "domestic violence" is a set of behaviors that cause physical, psychological, moral and social suffering or even sex with the woman [2]. He noticed sometimes through acts of physical, moral or psychological and sexual reactions which may cause significant consequences on the wellbeing of the victim.

The repetitive domestic violence that the woman suffered from intimate partner is a public health issue of great concern in view of its impact and its impact on health has [3] . According to the WHO report (2012), partner violence against women is responsible for $70 \%$ risk of intentional homicide and $40 \%$ for manslaughter. In the African region, this phenomenon is very common and its impact on the health of women is very considerable. Studies by Schuler (1992) and Brograd (1993) estimate that, on average, a woman in the household is the victim of intimate partner violence every 83 seconds and only 1 in 20 of this case is reported to third parties. people. UNICEF (2014) states that repetitive domestic violence in Congolese families has varied forms including offensive language, assault, rape, forced abortion, non-payment of dowry, various deprivations physical and financial or even relational, which can have a significant impact on the health of women, the lives of children and the social and economic development of the community. Although there are no reliable statistics on domestic violence in Democratic Republic of Congo (DRC), the Woman Action Network (RAF) reports Even while me the importance of this phenomenon in all layers of society Congo comfortable. The same source indicates that many women are slapped, beaten, verbally abused by their spouses in public or behind walls, humiliated and forced into sex with their partners, while others are deprived of these intimate relationships [4]. In the town of Kenge, In the Kwango Province, women are not spared violence in all its forms. The NGO New Dynamic of the Jeunesse Feminine (NDJF) the violence against the woman indicated in his report 2016 than in most families, women are beaten, insulted, humiliated publicly or even tortured behind walls or in public without any EU intervention even less of public power [5]. Thus, the goal pursued by this study was to determine the psychosocial factors associated with domestic violence done to the woman by her husband. To achieve this goal, the assigned goals are to identify the psychosocial factors that influence the occurrence of domestic violence against women by her husband in the Kenge City.

\section{Literature Paper}

Perl was domestic violence when a person performs or threat to exercise physical, psychological or sexual abuse within a family, spousal or marital or being dissolved. This definition shows that domestic violence also occurs in couples who do not live together or separately [6]. Violence against women persists in all countries of the world, whether perpetrated by states and institutions, or in groups, family or community. This violence, present everywhere, in the private and public sphere, is deeply rooted in the sociocultural system of the victims. The role of society and culture as determinants of violence against women must then be studied, given the many justifications developed on their behalf $[7,8]$. No woman, no girl in the world is immune from violence because of her sex. At any time in their life, in their infancy, childhood, adolescence, adulthood or old age, women may suffer physical or mental abuse and sexual violence and live in fear. The perpetrator of violence is mostly a man, a person known to the victim, most often a loved one. No living space for women and girls is protected. And spaces usually considered the most protective: the family, the couple where love, care and security should normally reign, are those where the most violence occurs [9]. From blows to death, the home is a place of threats, not of protection. According to World Bank data, rape and spousal violence pose a greater risk to a woman aged 15 to 44 than cancer, road accidents, war and malaria combined. Private home is where much of the violence against women and children occurs and is perpetuated. They are beaten, victims of sexual violence or otherwise abused, by intimate partners, family members. Several global surveys suggest that half of female homicide victims are killed by their spouses or former spouse or companions [10].

The numbers in the world are overwhelming. According to a WHO report in 2013, 35\% of women have experienced physical and or sexual partner of theirs intimate, or violence by people other than their partners. According to statistics , up to $71 \%$ of women experience violence. Most of violence committed within the family and the couple, almost a third of all women who had a relationship have experienced physical and/or sexual intimate partner and 38\% of total killings of women are carried out by intimate partners [11]. In France, the results of the surveys in 2014 show that 118 women and 25 men were killed by their spouse or former spouse. There are also 16 women and 6 men killed by their partners unofficial (lovers, boyfriends, relationships episodic); and 35 minors were killed in the contexts of violence within the couple. On average, each year, an estimated 223,000 women between the ages of 18 and 75 are victims of domestic violence in its most serious forms (physical and/or sexual violence by their spouse or former spouse). Of these, $14 \%$ filed a complaint. The victims estimate that $68 \%$ of these victims have had a rather or very significant impact on their psychological health and 54\% that they have caused disturbances in their daily lives [12]. In 2016, more than 85,400 victims lodged complaints of physical violence by their spouses or former spouses 
according to the Gendarmerie and the National Police (+3\% between 2015 and 2016). Women are most represented among the victims, with nearly 9 women victims. In 2016, more than 2,000 victims of rape by a spouse filed a complaint with these services. These rapes also mainly concern female victims [13]. In several West African countries, Oxfam (2009) argues that violence against women reflects inequalities in the relationship between men and women. They originate from the social system based on patriarchy. This system creates and perpetuates prejudices and social stereotypes that are harmful to women, which keeps them in an almost permanent state of domination. The weight of customs, traditions and the misinterpretation of religions lead to the marginalization of women and their relegation to the background. Causes of violence are multiple and can be structural : sociocultural constraints (social prejudices and stereotypes, harmful traditional and customary practices, differentiated education, social pressure); poverty (economic dependence of women); the coexistence of several sources of rights (modern, customary and Muslim) further complicates the situation of women who are often harmed; ignorance (illiteracy, ignorance of rights by women, women's complicit silence).

On the social level, we note the dislocation of the family unit (higher risk of delinquency of children, etc.); the psychological destabilization of the mother and the children; prostitution; the low enrollment rate of girls; non-participation of women in decisionmaking. On the economic level there is the impoverishment of women and households; the cost to the family and society; loss of income due to women's lack of participation in development activities and decision-making. On the sanitary level: we note the physical lesions, traumatisms and other psychological disorders; premature and unwanted pregnancies, abortions; STI, HIV AIDS; obstetric fistula [14-17]. In Algeria, the number of cases of violence against women is increasing. In $64.9 \%$, the place of the aggressions is the family home (husband, brother, child), $50 \%$ of the victims of violence are married, $50 \%$ of the cases denounced by the married or married women relate the aggressions committed by the husband or the former spouse. Women working outside the home are more likely to be victims of violence than their unemployed peers [18]. Violence has immediate effects on women's health, in some cases fatal. Its consequences on physical, mental and behavioral health can also persist long after it has stopped $[19,20]$. Several general risk factors are identified as promoting violence (low level of education, child abuse, family violence, alcohol, multiple partners, tolerance of violence and gender inequality, etc.). Among the risk factors for sexual violence are beliefs about family honor, the obligation of virginity before marriage, ideologies about "the irrepressible sexual needs of men" and weak legal sanctions. The degraded economic situation can increase women's vulnerability to violence. The risks of violence against women may increase according to different individual, family, community, environmental, economic and societal factors . Violence can be verbal, economic (refuse that joint working, deprive it of its resources, confiscate the means of payment, etc.) or administrative (retention papers, paperwork, etc.). Psychological violence is insidious and causes major emotional damage (control of movements, shouting, threats, devaluing the victim, psychic hold, etc.). The consequences of violence on the health of victims have an impact on their ability to be at work and in a situation of working well even though work is a guarantee of autonomy that can be crucial in a separation decision . 95\% of women who suffer psychological violence at work lose their job, by dismissal or resignation. It is a double punishment for victims of violence. Children are co-victims of domestic violence. In 2015, 36 children were killed in domestic violence. 96 children were orphaned, 68 were present at the time of the incident and in 8 cases, it was the child who gave the alert [21-26].

\section{Materials and Methods}

\section{Description of the Mi Place of Study}

This study was mainly conducted in the City of Kenge, capital of Kwango Province, DRC. It is built a few meters above the Wamba River . It is located at 5 latitude, 17 East longitude, and an average elevation of $555 \mathrm{~m}$ above sea level. It is in the humid tropical climate of the AW3 type of the Köppen classification. This city rests on plateaus intersected by deep valleys, and sometimes hills and on sandy soil in a predominantly savannah configuration interspersed with forest galleries bordering streams. It has 153, 290 inhabitants (Town Hall of the City of Kenge, 2013) divided into 15 districts.

\section{Sampling and Technique Collection of Donations}

\section{Mological approach méthod}

This study focuses on the data collected in the period from March to July 2017 During a cross quantitative survey by technique tenancy (interview) conducted face to face with women in households. The sample of this study is probabilistic, selected in a simple random way. S size is 165 subjects while the proportion of domestic violence eta i t $0.11 \%$. The following formula of Fischer was altered for the sample size:

$$
n=z \alpha^{2} * \frac{p \cdot q .}{d^{2}}
$$

[Equation 1]

Or,

$\mathrm{Z}$ is the normal $95 \%$ confidence level parameter (in practice $=$ 1.96);

$\mathrm{p}$, proportion of the target population that has been the victim of sexual violence; it is $11 \%$ for this study.

$q=1-p$, the proportion of subjects who have not been victims of sexual violence; she is $89 \%$;

$d$, the degree of precision of the estimate, is in practice $5 \%$.

\section{Selection Criteria}

Forbes included in the sample, the person had to be a married woman living in the city of Kenge and diving with my partner 
sculling in a family environment. She must also have s communicate in Kikongo, Lingala, English f or another local language. His present it the day of the survey was also required.

\section{Exclusion Criteria}

E is excluded from the sample:

a) Any subject who voluntarily ment refusal ed to participate in the study

b) Any woman in a state does not allow him to carry out an interview.

\section{Technical analysis data}

The data thus collected were essentially analyzed using descriptive and inferential statistics and qualitative analysis. Descriptive statistics consisted mainly of calculating frequencies based on the following equation (Equation 2 ) :

$$
f=\frac{F_{o}}{F_{A}} * 100
$$

[Equation 2]

Or,

$$
\begin{aligned}
& \mathrm{f}=\text { Relative frequency } \\
& \text { FO = Frequency observed }
\end{aligned}
$$

$\mathrm{FA}=$ Expected frequency

The inferential analysis using the chi-square test (国) has verified the links between domestic violence inflicted women and sociodemographic factors, society cultures and associated psychoenvironmental violence. This test has vat VERIFY allowed the null hypothesis that there was no significant relation entre the expected distribution of numbers of abused women (E) and observed that $\mathrm{e}$ da ns the distribution are suspected psychosocial factors explains domestic violence inflicted Oley's (0). Thus, the century following assumptions have been testing:

$\mathrm{H}_{0}: \mathrm{E} \neq 0$, there is a significant difference ent $\mathrm{r}$ e distributions of $\mathrm{E}$ and $\mathrm{O}$

$\mathrm{H}_{1} \mathrm{E}=0$, There 'a a u cu not significant difference between the distributions of $\mathrm{E}$ and $\mathrm{O}$

From an analytical point of view, the chi-square statistic $\left(\mathrm{Khi}^{2}\right.$ or $\mathrm{Q}^{2}$ ) is represented by the following formula (Equation 2):

$$
\chi_{d d l: p}^{2}=\sum \frac{\left(E_{j}-o_{i}\right)^{2}}{o_{i}}
$$

[Equation 3]

Where,

Ei, the $i_{\text {th }}$ actual expected enrollment of abused women

$\mathrm{Oj}$, the $\mathrm{j}_{\mathrm{th}}$ observed effective than the distribution of psychosocial factors associated with domestic violence to the women, the degree of freedom (equal to nk) $\mathrm{n}$, the total number of the sample

$\mathrm{k}$, the number of estimated parameters ( equal to the number of factors)

$\mathrm{p}$, the signi fi cation rate (equal to the probability of failure of Ho )

The chi-square statistic was tested at the $5 \%$ significance level $(\mathrm{p}=0.05)$ using computer software MS Excel 2010 and SPSS 17.0. The evaluation was based on research questions and earlier literature thanks to qualitative analysis. The latter was essentially based on a method of analyzing century themes, concepts or similar patterns. She allowed of INTERPRET there in accordance with the previous studies on domestic violence inflicted Oly are by their husbands. All were presented in the form of frequency tables and graphs.

\section{Results of Analysis}

\section{Sociodemographic Factors Associated with Domestic Violence}

The data of the Figure 1 indicate that 134 subjects or $81.2 \%$ are 25 years old and over, while 31 or $18.7 \%$ are under 25 years old. Generally, the youngest are more exposed to violence. Often, they are respectful of their husbands and react less to them. But of age, only is still exposed to violence. Table 1 actually shows a very significant influence of psychic maturity (measured by the age of 24 after the first has born $\mathrm{n}$ ) on the mastery of domestic violence $\left(\mathrm{Chi}^{2}=6.3\right.$ ; $\mathrm{dd} 1=1, \mathrm{p}=0.01$ ). The Figure 2 shows that 147 out of 165 respondents ( ie $89,1 \%$ ) are alphabets, those that can be implied than a domestic conflict known to all, and 18 are literate (0 or 1,9\%), those with a certain level of formal education and who may well be master before a conflict. Reality on the ground has led us to note that in homes where women are uneducated, there is often violence that is due to its weak ability to understand some things that, however, are simple. It creates useless misunderstandings and tensions between partners that end in violence. The other trend is that in households where the woman had a high level of education, the violence was related to the fact that the woman was employed much more than the man. This violence was based on two aspects: the inferiority complex of the man in the place of his wife, always seeking to assert his authority over her and on the other hand the lack of consideration of the woman in the place her husband believes that her contribution is greater in the family budget and therefore it is more important of all. The other aspect aggravating this violence is the poverty and the total dependence that this lack of education of the woman brings because it cannot reach a decent job.

Table 2 confirms the assumption that the IVEA destruction has a positive influence on the self-control to a conflict domestic (Chisquare $=4.01 ; \mathrm{ddl}=1 ; \mathrm{p}=0,04)$. 


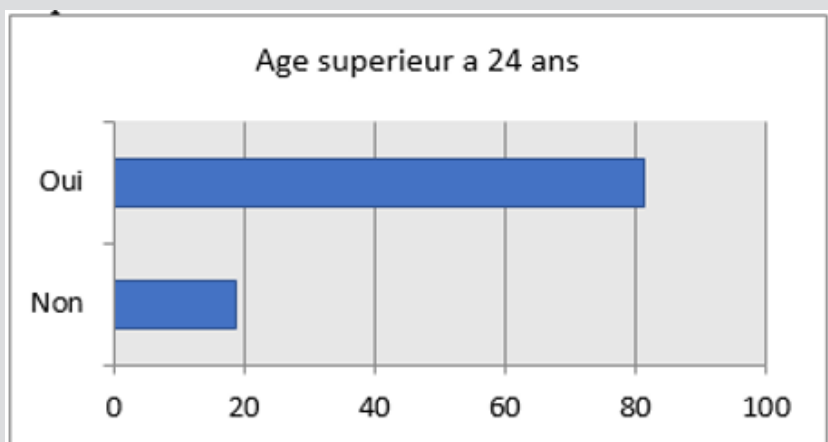

Figure 1: Classification of respondents by age of maturity ed psychic.

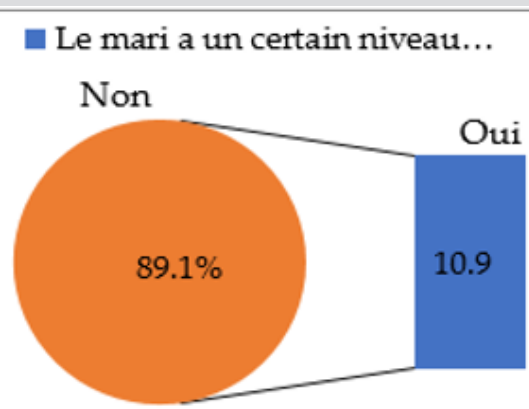

Figure 2: Distribution of respondents by level instruction.

Table 1: Relationship between age of respondents and a domestic violence.

\begin{tabular}{|c|c|c|c|c|}
\hline \multirow{2}{*}{$\begin{array}{c}\text { Age of the respondents } \\
\text { ( } \mathbf{2 5} \text { years old) }\end{array}$} & \multicolumn{4}{|c|}{ Domestic violence } \\
\cline { 2 - 5 } & Effective & $\%$ & Effective & $\%$ \\
\hline No & 19 & 11.5 & 11.5 & 7.2 \\
Yes & 86 & 52.1 & 52.1 & 29 \\
\hline Total & 105 & 63.6 & 60 & 36.2 \\
\hline
\end{tabular}

Table 2: Relationship between the levels of instruction and violence has domesticated.

\begin{tabular}{|c|c|c|c|c|}
\hline \multirow{2}{*}{ Level of education } & \multicolumn{4}{|c|}{ Domestic violence } \\
\cline { 2 - 5 } & \multicolumn{2}{|c|}{ Yes } & \multicolumn{2}{c|}{ No } \\
\cline { 2 - 5 } & Effective & \% & Effective & $\%$ \\
\hline literate & 96 & 58.1 & 51 & 51 \\
A n lphabète & 11 & 6.6 & 7 & 7 \\
\hline Total & 107 & 648 & 58 & 35.1 \\
\hline
\end{tabular}

\section{Sociocultural Factors Associated with Domestic Violence}

Table 3 shows that 55 subjects is $33.3 \%$ of investigated have contracted the marriage count; 47 subjects or $25.5 \%$ followed the customary pattern, civil and religious; 33 subjects $20 \%$ contracted only a de facto marriage and 30 subjects, $18.2 \%$ followed the customary and civil scheme. Here we are witnessing several types of union: customary marriage, civil and religious. There are also those who live in a common-law relationship. Kenge, which was once a city, has become, thanks to decentralization, a city and chief town of Kwang Province. As in all cities, the prevailing culture of marriage follows a long process of knowing: the marriage custom of paying dowry in the woman's parents and civil ceremonies are in the office of the Town Hall and ending with a religious ceremony. All these procedures require the Husband much more means than the vast majority does not have. Women are becoming increasingly demanding in this matter and believe that man must complete all these procedures for they feel are honored. In homes where the wife has never been married in all these forms, there are from time to time discontent on her part towards her husband . And at every little discussion, the woman always reminds her husband that he must reserve to inflict some treatment on him or to demand too much because she thinks she has never been married in any form. The man is not always willing to endure this kind of talk often launches dan s violence. Other women attribute the misfortune that happens to their family to the dissatisfaction of the parents for not having touched their date (Table 4). Husbands on their side perceive this act differently. Some think that women exert pressure on them while financially they are not ready to do all these things. As a result, the violence erupts against the woman.

Table 3: Distribution SURVEY ties by marriage contracted form.

\begin{tabular}{|c|c|c|}
\hline Type of social contract & Effective & \% \\
\hline Customary only & 55 & 33.3 \\
\hline Customary and civil & 30 & 18.2 \\
\hline Customary, civil and religious & 47 & 25.5 \\
\hline Marriage in fact & 33 & 20 \\
\hline Total & 165 & 100 \\
\hline
\end{tabular}

Table 4: Relationship between the form of marriage and a domestic violence.

\begin{tabular}{|c|c|c|c|c|}
\hline \multirow{2}{*}{ Type of social contract } & \multicolumn{4}{|c|}{ Domestic violence } \\
\cline { 2 - 5 } & \multicolumn{2}{|c|}{ Yes } & \multicolumn{2}{c|}{ No } \\
\cline { 2 - 5 } & Effective & $\%$ & Effective & $\%$ \\
\hline Customary only & 36 & 21.8 & 19 & 19 \\
Customary and civil & 18 & 10.9 & 12 & 12 \\
Customary, civil and & 30 & 18.1 & 17 & 17 \\
religious & 22 & 13.3 & 11 & 11 \\
civil union & 106 & 64.2 & 59 & 35.7 \\
\hline Total & & &
\end{tabular}

\section{Psycho-Environmental Factors Associated with Domestic}

\section{Violence}

Figure 3 indicated that 145 of the 165 respondents, 87.9\%, have experienced conflict s against 20 subjects (ie $12.1 \%$ ) who have not experienced conflict. We observed that women in whom there was already and conflict history have suffered more violence than those of families are without conflict history. It should be noted that disagreements between partners is already a favorite medium of violence (Tables 5 \& 6). The woman is the most victim of these conflicts because she suffers all forms of violence from her 
husband even for things of which she is sometimes right. From the analysis in Table 6 there is a very significant influence aggressive behavior of the husband from childhood on es s violence recorded in some households is Kenge $\left(\mathrm{Khi}^{2}=13.58\right.$; $\mathrm{dOF}=1$ and $\left.\mathrm{p}=0.002\right)$. The interviews revealed that aggressive husbands were more violent towards their wives. Table 7 establishes a very significant relationship between use of unconventional drugs by her husband and a domestic violence made to the woman $\left(\mathrm{Khi}^{2}=17,039\right.$; dOF $=1 ;=p=0.01$ ). This consumption of drugs may well explain the aggressive behavior of housewives.

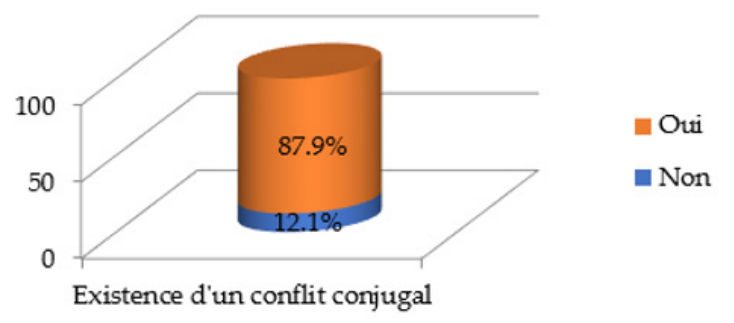

Figure 3: The existence of marital conflict among the respondents.

Table 5: Relationship between the existence of marital conflict and domestic violence.

\begin{tabular}{|c|c|c|c|c|}
\hline \multirow{2}{*}{$\begin{array}{c}\text { Existence of marital } \\
\text { conflict }\end{array}$} & \multicolumn{4}{|c|}{ Domestic violence } \\
\cline { 2 - 5 } & \multicolumn{3}{|c|}{ Yes } & \multicolumn{2}{c|}{ No } \\
\cline { 2 - 5 } & Effective & $\%$ & Effective & $\%$ \\
\hline Yes & 28 & 16.9 & 16.9 & 9.0 \\
No & 93 & 38.1 & 38.1 & 17.5 \\
\hline Total & 121 & 73.3 & 44 & 26.6 \\
\hline
\end{tabular}

Table 6: Relationship between aggressive behavior and a domestic violence.

\begin{tabular}{|c|c|c|c|c|}
\hline \multirow{2}{*}{ Aggressive behaviour } & \multicolumn{4}{|c|}{ Domestic violence } \\
\cline { 2 - 5 } & \multicolumn{3}{|c|}{ Yes } & \multicolumn{2}{c|}{ No } \\
\cline { 2 - 5 } & Effective & $\%$ & Effective & $\%$ \\
\hline Yes & 15 & 9.0 & 6 & 3.6 \\
No & 106 & 64.2 & 38 & 23.0 \\
\hline Total & 121 & 73.3 & 44 & 26.6 \\
\hline
\end{tabular}

Table 7: Relationship between usage drugs by her husband and a domestic violence.

\begin{tabular}{|c|c|c|c|c|}
\hline \multirow{2}{*}{ Drug use } & \multicolumn{4}{|c|}{ Domestic violence } \\
\cline { 2 - 5 } & \multicolumn{3}{|c|}{ Yes } & \multicolumn{2}{c|}{ No } \\
\cline { 2 - 5 } & Effective & \% & Effective & \% \\
\hline Yes & 19 & 11.5 & 11 & 6.6 \\
No & 89 & 53.9 & 46 & 27.8 \\
\hline Total & 108 & 65.4 & 57 & 34.5 \\
\hline
\end{tabular}

\section{Discussion of Results}

\section{Discussion on Socio Demographic Factors Associated with Domestic Violence}

With regard to demographic variables, the results obtained make it possible to establish a significant relationship between age and the occurrence of domestic violence against women by her husband. $\left(\mathrm{Khi}^{2}=11.6, \mathrm{ddl}=1\right.$ and $\mathrm{p}=0.01$ ). The young women whose age is under 25 years seem to be very exposed e s violence. Being very young, they are generally docile, very reserved and respectful toward their s husband, with less reaction, when it lasts talking not. The Federal Bureau of equality between women and men (2012), noted that the art demographic, socioeconomic and sociocultural characteristics allow in first line to portray the social groups that have a risk raised to be affected by violence. Among these factors that play a fundamental role, he noted the great age difference between partners, very young woman. Several other studies on domestic violence confirm the relationship between age and domestic violence. They noted that the has domestic violence knows several forms that can manifestly have isolated way or combi born. Moreover, these forms differ depending on the type of relation, sex and age of the per PERSONS involved [27-30]. The Parliamentary Assembly of La Francophonie ( 2010) notes that young women are particularly vulnerable to sexual violence . However , the study conducted by Salmona (2014) emphasizes that no woman, no girl in the world is immune from violence because of her sex. At any time in their lives, from infancy, childhood, adolescence, adulthood or old age, women may experience physical or mental abuse and sexual violence and live in fear. No living space for women and girls is protected. And the spaces usually considered the most protective: the family, the couple, where love, care and security should normally reign, are those where the most violence occurs.

Analysis of the socio-economic variables allowed us to detect that the level of education is a factor which determines the occurrence of the conjugal violence of which often the women are victims $\left(\mathrm{Khi}^{2}\right.$ of 4,01, ddl 1 and pp 0,04). The reality on the ground shows that in homes where women are uneducated, there is often violence that is due to their weak abilities to understand some things that, however, are simple. It creates useless misunderstandings and tensions between partners that end in violence. This lack of education also exposes women to economic dependence because they cannot take paid employment and therefore, she remains in poverty. This is the same case for the male partner. The various studies conducted around the world have confirmed these facts. They show that among the general risk factors for violence include the low level of education, the economic dependence . Fighting violence also means fighting for genuine equality and allowing all , boys and girls, to have quality access to education, health, housing and work. If studies show that a high level of education is the best 
remedy against sexism and its violence, illiteracy and academic failure remain a major problem [31]. Other studies reveal even that has domestic violence is related to other social determinants of health including living conditions, poverty, employment, culture and education. A poor socio-economic environment can also lead to stress and inability to cope with problems, which in turn result in acts of violence. The study Plug (2009) has revealed that wife beating would happen more often in societies where men hold economic and decision-making power in the household, and where adults routinely resort to violence to resolve their conflicts.

The other trend of the study shows than in households where the woman had a high level of education compared to men , the violence was related to the fact that the woman held a much more lucrative job than that of the man. This violence often rested on two aspects: the inferiority complex of the man to the place of his wife and on the other side the lack of consideration of the woman to the place of her husband who thinks that his contribution is more important in the family budget and therefore it is more important of all. These results are similar to those of Josse (2007), which stipulate that the More educated women are at greater risk of violence, including sexual violence from their intimate partner. Because they become more autonomous, they are more resistant to patriarchal norms. To regain control, some men resort to violence. The link between poverty and violence (especially sexual) is established through a form of crisis of male identity. Every society has its "positive" models and ideals of masculinity and virility, where material consumption often occupies a significant place. When a man does not meet the expectations of male "success", his ideals are broken and perverted. The aggression of women and sexual conquest are then normalized, men returning their aggression against women that they can no longer dominate in the traditional patriarchal mode or live on the economic level.

\section{Discussion of the Factors Sociocultural Associated with Domestic Violence}

In socio-cultural factors, our study focused more on the form of marriage that was detected as a factor associated with domestic violence. $\left(\mathrm{Khi}^{2}=4.02\right.$, dof $=3$ and $\left.\mathrm{P}=0\right)$. Here we see several types of union: customary marriage, civil and religious . There are also those who live in a common-law relationship. Kenge, which was once a city has become through decentralization, a city and capital of the province of Kwang o. As in all cities, the culture of marriage is a long process. Customary marriage which consists of paying the dowry to the woman's parents, then the civil ceremonies at the town hall office to finish with a religious ceremony. All these procedures require more means that the vast majority of men did not. In homes where the woman has never been married in all these forms, there are occasional discontent on the part of her or even her family members towards her husband. At every little discussion, the woman always reminds her husband that he must reserve the right to inflict some treatment on him or to demand too much because she considers that she has never been married in any form. Now the man African are not always willing to endure this kind of talk because it naturally wants dominion over his wife, embarks dan s violence.

Other women attribute the misfortune that happens to their family to the parents' dissatisfaction at not having touched the dowry. Husbands on their side perceive this act differently. Some think that women exert pressure on them when they are not financially ready to do all these things. As a result, the violence erupts against the woman. WHO (2012) from him indicates that various factors including socio-cultural factors are at the root of domestic violence repetitive $s$ inflicted $s$ the woman by her husband. It notes that Violence against women and girls is found in all countries and cultures, rooted in the social and cultural attitudes and norms that favor men over women and boys over girls. Violence can take many forms, including dowry-related violence. However, the nature or severity of the effects of violence may be influenced by context-specific factors, such as: poverty; gender inequality; cultural or religious practices. The Francophone Parliamentary Assembly (2010) points out that many of the other traditional practices that are harmful to women and children include burns, scars, violent initiation rites, force-feeding, forced marriage, related violence. dowry, exorcism and witchcraft. Masson (2017) notes, moreover, that, the dowry, initially as a customary symbolic act in the eyes of the community and both families to make the marriage a reality, for some families it becomes a source of punctual income.

\section{Discussion on the Psycho-Environmental Actors Associ- ated with Domestic Violence}

The living environment of women has a very significant impact on the occurrence of violence. The results of the study show us that there is a highly significant relationship between the psychoenvironmental variables precisely the existence of marital conflicts and the occurrence of domestic violence. This study has observed that women in whom there was d es conflict history have suffered more violence than families without a history of conflict. It should be noted that disagreements between partners is already a favorite medium of violence. The woman is the one who is the most victim of these conflicts because she undergoes all forms of violence from her husband even for things for which she is sometimes right. The study conducted in Switzerland reveals that there is a clear correlation between frequent conflicts in the couple and the appearance of violence. However, it is misleading to think that conflict is the cause of violence. (Federal Office for Equality between Women and Men, 2012). The co marital conflicts or discord in the couple are the most consistent markers of violence against the partner. Interactions almost daily and the fact of sharing the home of the aggressor, when it is the spouse, contribute to increase opportunities of incidents and exposure to repeated violence. The behavior of the individual is an important factor in the occurrence of domestic violence. The results of this study have linked positive 
between the behavior aggressive and the occurrence of violence. Aggressive husbands are more violent toward their wives. The results of several studies conducted around the world have also shown that the risk of perpetrating or experiencing violence may increase according to various factors including the individual factor. Thus, the Individual scale includes a person's personal history and biological characteristics that will influence their behavior.

Other representative studies reveal that the characteristics of the (male) perpetrator of violence have a more significant influence on the risk of violence in relationships than that of women victims. It should be noted, however, that a punctual aggressive behavior in a situation of conflict can be transformed into violent behavior and systematic coercive control, for example when the attacks of one person against the other multiply and asymmetrical structure of the relationship results. Apart from the aggressive behavior of the individual, he results of this study showed that women whose husbands had individual behavior of drug use were more exposed to suffer violences. These results are consistent with those of Gelles (1993) who indicate that excessive alcohol consumption can also increase family violence by escalating disputes in couples. In this vein, Kantar (1998) states that apart from family history and alcohol abuse, anger and nervousness are capable of leading to violence against the woman in a conjugal environment. A study conducted in France, confirmed that 32\% victims of violence Declarant have that the perpetrator was under the influence of alcohol or drugs at the time of passage to the act. The study by Lamy (1991) notes that in the majority of the cases studied, a problem of alcohol and / or drug use was also present and perceived as one of the triggers of the violence .

\section{Conclusion and Recommendations}

\section{Conclusion}

This study focused on the psycho-social actors associated with domestic violence inflicted on women by their husbands in Kenge . The goal we pursued was to determine the factors associated with domestic violence inflicted on women by their husbands. It is true that violence to women is real on and exist you in our city of Kenge in all its forms: physical, moral, psychological and verbal. The results of the study suggest that violence against women in the conjugal roof by their husbands is associated with demographic factors (age); socio-economic (level of education , poverty); socio-cultural (form or types of marriage); Individuals (aggressive behavior since childhood, drug use) and environmental factors (antecedents of family conflict).

\section{Recommendations}

Given the above results, it is recommended reliable than the Congolese government identifies in clear terms and legislate what constitutes an act of violence against women. It will also help to vote e $t$ to enforce laws in protecting social woman while holding it by provision s regulatory setting forth are remedies in order to facilitate the reporting of acts of violence experienced. It is finally recommended both administrative and political authorities to raise awareness of domestic violence and to set up ad hoc mechanisms to prevent it. Thus, the husbands should work with the authorities and working with them for the promotion of women's rights and equality between men and women. The s women help their husbands well by denouncing all acts of violence. In doing so, they have to opt have an attitude that the savings are of violence domestic.

\section{References}

1. (2010) Parliamentary Assembly of La Francophonie. Violence against women and children in the intimate space. Report of the meeting of the Network of Parliamentary Women, Dakar, Senegal.

2. Bailard, TJ Saltzman LE, Gazmararian JA, Spitz AM, Lazorick S, et al. (1998) Violence during pregnancy: measurement issues. American Journal of Public Health 88(2): 274-276.

3. Black (1994) Factors of violence against women. Ed RPL, Bulgaria.

4. (2013) Town Hall Office City of Kenge Administrative census of the population of Kwango- Report of the Office of the Town Hall of Kenge . Kenge , Kwango Province, Democratic Republic of Congo.

5. (2012) Federal Office for Equality between Women and Men. Domestic violence: definition, forms and consequences. Federal Department of the Interior, Switzerland.

6. (2014) CENI, Independent National Electoral Commission Kinshasa: Electoral Cartography, Kinshasa: CENI, Democratic Republic of Congo.

7. (2010) National Collaborating Center for Aboriginal Health. Family Violence : A Social Determinant of First Nations and Métis First Nations Health.

8. (2010) Regional delegation for women's rights and equality in Ile-deFrance. Domestic violence mechanisms, France.

9. Dutton DG (1998) Domestic aggression against women: psychological perspectives. Edition of the University of British Columbia .

10. (2014 ) Woman with Fone. Domestic violence against women in the Democratic Republic of Congo. A guilty silence. Bukavu Democratic Republic of Congo.

11. Fortin MF (1986) Processes research from conception to realization. Quebec : Edition Décaris , Quebec, Canada.

12. R Gelles (1993) Alcohol and other drugs are associated with violence they are not causes. In: RJ Gelles, Loseke DR (Eds.), Current controversies on family violence, Thousand Oaks, Sage 171-181.

13. Javeau CL (1992) Questionnaire survey, manual for practitioners. Brussels : editions of the University of Brussels, Belgium.

14. Josse E (2007) Domestic violence. Some landmarks. Training document for Algerian professionals in charge of women victims of domestic violence. Algiers Algeria.

15. Lamy B (1991) Domestic violence in small coastal communities: an intervention project. Regional Health and Social Services Board of the North Shore, Canada .

16. Laroche D (2007) Context and Consequences of Spousal Violence against Men and Women in Canada, 2004, Quebec, Quebec Institute of Statistics pp. 117.

17. Masson V, Benoudji C, Sotelo S, Giselle Bernard R (2017) Violence against women and girls and resilience. Which links? What issues? What impacts? Perspectives of the Chadian context.

18. Magali Bouchon (2009) Violence against women gender, culture and societies. Practical approach. Technical Support Service for Operations (STAO), Doctors of the World. 
19. (2015) Ministry of the Interior, Decentralization and Security. New Provinces Programming Act. Kinshasa, DRC

20. (2015) Interministerial Mission for the Protection of Women against Violence and the Fight against Trafficking in Human Beings, MIPROF (2015) .Violence against women: the main data. The letter of the National Observatory of violence against women, Paris, France .

21. (2017) National Observatory of Delinquency and Criminal Responses, ONDRP Elements of measurement of violence within the couple. Annual Report 2017, Paris, France.

22. (2002) WHO, Violence against women in the family Technical Report Series No. 23/2002 Geneva, World Health Organization?

23. (2008) WHO, Anti-violence Strategy: A Practical Handbook Geneva, World Health Organization?

24. (2012) WHO, Understand and fight against violence against women Geneva, World Health Organization?

25. (2013) WHO, Violence against women: a global public health problem of epidemic scale New clinical and policy guidelines are published to guide the health sector's work.

26. (2014) WHO, Violence against women Geneva, World Health Organization?

\section{ISSN: 2574-1241}

\section{DOI: 10.26717/BJSTR.2019.18.003130}

Jean Jacques Kisaka Ngimbi. Biomed J Sci \& Tech Res

(C) This work is licensed under Creative

Submission Link: https://biomedres.us/submit-manuscript.php
27. Oxfam (2009). The fight against violence against women: testimonies from West Africa, Summer Feminist University, available on www.oxfam. qc.ca .

28. River D, Ronai E (2017) Combat violence against women in the Overseas. Opinion of the Economic, Social and Environmental Council on the delegation to the rights of women and equality and the delegation to the Overseas. Directorate of Legal and Administrative Information, editions of Official Journals, Mandature 2015-2020, France.

29. Salmona C (2014) The psychotraumatic consequences of violence against women. Professionals facing victims of domestic violence: psychological and legal approaches, cross-referencing. Institute of Victimology 92, Association Traumatic Memory and Victimology, available on memoiretraumatique.org

30. Thériault L, Gill C (2007) Social determinants of health and spousal violence: What are the links? Social Service 53 (1): 75-89.

31. (2013) WHO (World Health Organization) (2013), Global and Regional Estimates of violence contre women: Prevalence and health effects of intimate partner violence and non-partner sexual violence, WHO, Department of Reproductive Health and Research, London School of Hygiene \& Tropical Medicine South African Medical Research Council, Geneva.

\begin{tabular}{ll} 
BIOMEDICAL & Assets of Publishing with us \\
RESEARCHES & - Global archiving of articles \\
& - Immediate, unrestricted online access \\
\hline
\end{tabular}

